\title{
EVALUATION OF CHANGES IN THE UTILITY PROPERTIES OF A BASE MATERIAL AFTER THE APPLICATION OF THIN COATINGS OF WC/C, TIC/C AND A CARBON-BASED COATING: Ta-C
}

\author{
${ }^{1}$ Anna KAVÁNOVÁ, ${ }^{1}$ Totka BAKALOVA, ${ }^{1}$ Lucie SVOBODOVÁ, ${ }^{2}$ Mojmír JíLEK, ${ }^{1}$ Pavel KEJZLAR, \\ ${ }^{1}$ Petr LOUDA \\ ${ }^{1}$ Department of Material Science, Faculty of Mechanical Engineering, Technical University of Liberec, \\ Czech Republic, EU, anna.kavanova@tul.cz, totka.bakalova@tul.cz, lucie.svobodova@tul.cz, \\ pavel.kejzlar@tul.cz, petr.louda@tul.cz \\ ${ }^{2} S H M$ Šumperk, Šumperk, Czech Republic, EU, jilek@shm-cz.cz \\ https://doi.org/10.37904/nanocon.2019.8557
}

\begin{abstract}
Tribological coatings are mainly used to reduce adhesive wear, which often leads to the seizure or the formation of cold welds. The low coefficient of friction and good sliding properties make it ideal for applications with low lubrication or even dry running. The result is an ideal way to reduce surface fatigue and tribo-oxidation. Tribological coatings have good sliding properties, a low coefficient of friction and low adhesive wear. Thin layers of WC/C and TiC/C of the MeC/a-C: $\mathrm{H}$ coating group were deposited onto the surface of ISO 683/1170 steel. The third tribological coating deposited on the same substrate was a ta-C coating - a tetrahedral amorphous layer (stoichiometry: $\mathrm{sp}^{3}$ bonds $>50 \%$ ). Tribological measurements were performed at a load of $10 \mathrm{~N}$, a rotational speed of $60 \mathrm{rpm}$, and with a counterpart of ceramic material $\mathrm{Al}_{2} \mathrm{O}_{3}$.
\end{abstract}

Keywords: Nanocomposite coatings, surface morphology, mechanical properties, tribology and wear

\section{INTRODUCTION}

Thin coatings are used to protect the substrate and improve the useful properties of components. Insufficient lubrication and dry friction can occur during the working process. Therefore, thin layers can be applied (deposited on a certain substrate), which can perform the function of a lubricant [1]. The addition of metal to the carbon layers can in some cases improves the mechanical and tribological properties [2], for example a thin layer of WC/C that provides, chemical inertness and low coefficient of friction (0.12 to 0.15$)$ [3]. WC/C coatings offer good adhesion to the base substrate, which is an integral part of industrial use [1] and a large modulus of elasticity [4]. WC/C layers contain a nanocrystalline WC layer with and an amorphous $C$ phase [4]. Tungsten carbide with amorphous carbon is used in technical applications such as bearings, pumps, compressors, gear wheels, tools, [5] for anti-corrosion components, and to protect aircraft engine components etc. [6]. DLC layers are used in hard drives, shavers, damage-resistant glass, electronics, medicine and the automotive industry [7,8]. There are different types of DLC layers, which differ in composition, method of preparation and properties. One type of DLC layer is a ta-C coating, which has a low coefficient of friction and is wear resistant [9]. Diamond-like tetrahedral amorphous carbon (ta-C) films, which contain no hydrogen and high content of $\mathrm{sp}^{3}$ bonds, have a very high hardness and elastic modulus (up to $600 \mathrm{GPa}$ ) [10]. TiC/C coatings have good sliding properties and is wear resistant. This type of coating is used as a protective coating with high hardness and toughness [11]. Mechanical and tribological properties are influenced by deposition conditions [12,13]. The modulus of elasticity of TiC/C thin films ranges from 160 to $430 \mathrm{GPa}$, nanohardness from 13 to $44 \mathrm{GPa}$ and the coefficient of friction is around 0.14 . TiC/C coatings are suitable for application on tools or machine parts [1].

The aim of this research is to improve the utility properties of surfaces after modification of basic materials with thin layers labeled ta-C, WC/C and TiC/C. Surfaces after modification are intended to provide better friction 
properties in contact with the counter-body during dry friction. The surface modification with the desired frictional properties was subsequently selected as suitable for a given industrial application.

\section{MATERIALS AND METHODS}

\subsection{Used thin layers}

For the experiment, thin carbon-based coatings: ta-C, WC/C and TiC/C (SHM s.r.o. and PLATIT a.s.) were applied on two steel substrates W.Nr. 1.7131 (with a hardness of 650 HV1) and W.Nr. 1.2379 (with a hardness of $730 \mathrm{HV} 1$ ). The surface roughness and morphology, nanohardness, adhesion to the base material, wettability, homogeneity, thickness of coatings, tribological behavior and amount of wear were evaluated on the prepared coatings. Table 1 shows the deposition conditions of the investigated thin coatings. PVD technologies used by SHM s.r.o. are based on two basic coating principles: low-voltage arc vapor deposition and magnetron sputtering. All thin films used in the research were applied by magnetron sputtering.

Table 1 Thin coating deposition conditions

\begin{tabular}{cccccc}
\hline Thin coating & $\begin{array}{c}\text { Deposition } \\
\text { temperature }\left[{ }^{\circ} \mathrm{C}\right]\end{array}$ & $\begin{array}{c}\text { Overall magnetron } \\
\text { performance }[\mathrm{kW}]\end{array}$ & $\begin{array}{c}\text { Magnetron power } \\
{\left[\mathrm{W} / \mathrm{cm}^{2}\right]}\end{array}$ & $\begin{array}{c}\text { Pretension } \\
{[\mathrm{V}]}\end{array}$ & Pressure $[\mathrm{Pa}]$ \\
\hline ta-C & $110-150$ & 10 & 500 & 100 & 0.3 \\
WC/C & $150-200$ & 5 & 20 & 100 & 0.6 \\
TiC/C & $300-400$ & 7 & 30 & 300 & 0.7 \\
\hline
\end{tabular}

\subsection{Used methods of thin film evaluation}

The nanohardness and elastic modulus of the coatings were evaluated by a CSM Instruments indentation tester (Berkovich evaluation method). The maximum penetration depth during the measurement was no more than $10 \%$ of the coating thickness.

A Zeiss Ultra Plus scanning electron microscope (SEM) equipped with an Oxford X-Max 20 energy dispersive spectrometer (EDS) was used for the local chemical analysis, homogeneity, and thickness of the thin layers. To minimize the influence of the substrate on the quant results due to the penetration of primary electrons through the deposited layers, the chemical composition of the layers was analyzed at an accelerating voltage of $10 \mathrm{kV}$. Before performing the SEM analysis, the samples were cleaned with a mixture of ethanol and water in an ultrasonic cleaner.

The coating surface morphology was evaluated using a Sensofar Metrology material confocal microscope according to the ISO 25178 standard. The used parameters were as follows: $S_{a}$ is the average arithmetic height (average surface roughness); $S_{z}$ is the maximum height (height between the lowest recesses and the highest projection). The size of the evaluated area was $1700.16 \times 1418.64 \mu \mathrm{m}$.

The coating adhesion was evaluated using a CETR UMI Multi-Specimen Test System. A scratch test was performed using a progressive load from 2 to $80 \mathrm{~N}$ at a speed of $10 \mathrm{~mm} / \mathrm{min}$ (according to the EN1071-3:2005 standard). The scratch test was performed at room temperature and a relative humidity of $36 \pm 2 \%$.

The wettability of the nanostructured coatings was investigated on a Surface Energy Evaluation system, which is designed primarily for contact angle measurement and determination of surface energy. It features a robust aluminum housing, a 1.3 Mpx USB 2.0 color camera that moves vertically, and a 2D horizontal sample table. Distilled water was used for the evaluation and the tested oil with the trade name Paramo CLP 320 was used to approach the real conditions. The wettability evaluation apparatus was prepared according to the planned methodology and the samples were handled using gloves. The room temperature during the measurement 
was $22{ }^{\circ} \mathrm{C}$, the air humidity was $36 \pm 2 \%$ and the drop volume used was $5 \mu \mathrm{L}$. Ten drops were dripped onto each of the investigated surfaces to ensure repeatability.

A tribometer for dry and liquid environments (Anton Paar Czech Republic s.r.o.) in the "Ball-on-Disc" mode was used to estimate the tribology properties of the thin coatings (ASTM G99-95). An essential part of the test measurement was a friction sensor. The coefficient of friction ( $\mathrm{CoF}$ ) between the unit and the disc was determined during the test measurement. Tribological testing was conducted using a ball made of $\mathrm{Al}_{2} \mathrm{O}_{3}$ with a diameter of $6.00 \mathrm{~mm}$, at a load of $10 \mathrm{~N}$ and at room temperature and a humidity of $34 \pm 2 \%$. The rotation speed during the experiment was $60 \mathrm{rpm}$ and the travelled distance was $500 \mathrm{~m}$.

\section{RESULTS}

\subsection{Morphology a surface roughness}

Figure 1 shows the surface morphology of the investigated coatings labeled amorphous carbon (ta-C), WC/C and TiC/C by SEM analysis.
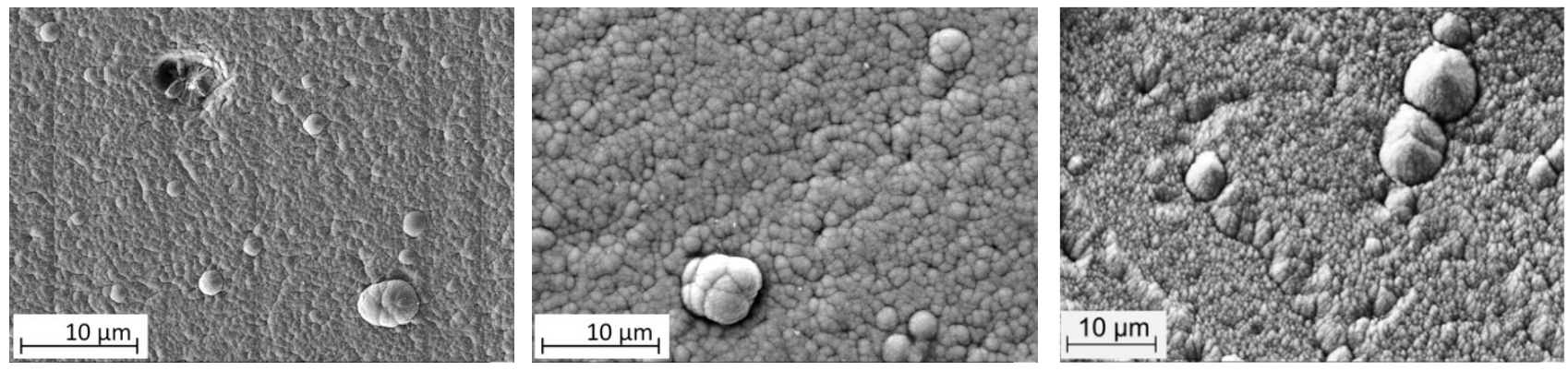

Figure 1 Surface morphology after deposition of a) thin coating of ta-C (left);

b) thin coating of WC/C (centered) and c) thin coating of TiC/C (right), evaluated by SEM

The measured surface roughness values (see Table 2) show that the modification of the surface leads to an increase in its roughness (according to the parameters $S_{a}$ and $S_{z}$ ). The greatest influence on the increase of surface roughness compared to the roughness of the base material was measured on the surface of the coating labeled TiC/C (W.Nr. 1.7131), then on the surface of the coatings labeled ta-C (W.Nr. 1.2379) and TiC/C (W.Nr. 1.2379).

Table 2 The measured surface roughness values $S_{a}$ and $S_{z}$ and their standard deviations in [ $\left.\mu \mathrm{m}\right]$

\begin{tabular}{|c|c|c|c|c|c|c|c|c|}
\hline \multirow{2}{*}{$\begin{array}{l}\text { Steel substrate } \\
\text { Thin coating }\end{array}$} & \multicolumn{4}{|c|}{ W.Nr. 1.7131} & \multicolumn{4}{|c|}{ W.Nr. 1.2379} \\
\hline & $\begin{array}{l}\text { W.Nr. } \\
1.7131\end{array}$ & ta-C & WC/C & $\mathrm{TiC} / \mathrm{C}$ & $\begin{array}{l}\text { W.Nr. } \\
1.2379\end{array}$ & ta-C & WC/C & $\mathrm{TiC} / \mathrm{C}$ \\
\hline \multirow{2}{*}{$S_{a}[\mu m]$} & 0.17 & 0.23 & 0.20 & 0.30 & 0.21 & 0.29 & 0.21 & 0.25 \\
\hline & \pm 0.02 & \pm 0.02 & \pm 0.01 & \pm 0.03 & \pm 0.01 & \pm 0.05 & \pm 0.01 & \pm 0.03 \\
\hline \multirow{2}{*}{$S_{z}[\mu m]$} & 1.39 & 1.82 & 2.30 & 2.61 & 2.08 & 3.18 & 2.16 & 2.66 \\
\hline & \pm 0.09 & \pm 0.11 & \pm 0.14 & \pm 0.16 & \pm 0.07 & \pm 0.16 & \pm 0.14 & \pm 0.12 \\
\hline
\end{tabular}

\subsection{Hardness and modulus of elasticity}

The parameters of the process of evaluation of nanohardness were as follows: approach distance $2 \mu \mathrm{m}$; linear loading with approach speed $1 \mu \mathrm{m} / \mathrm{min}$; max depth $0.30 \mu \mathrm{m}$; retract speed $2 \mu \mathrm{m} / \mathrm{min}$; loading rate $1.00 \mu \mathrm{m} / \mathrm{min}$; 
unloading rate $1.00 \mu \mathrm{m} / \mathrm{min}$; stiffness threshold $500 \mu \mathrm{N} / \mu \mathrm{m}$. Table 3 shows averaged values from five measurements of the hardness, modulus of elasticity and the plasticity index $(\mathrm{H} / \mathrm{E})$.

Table 3 The values of nanohardness and elastic modulus of the coatings in [GPa]

\begin{tabular}{lcccccc}
\hline Steel substrate & \multicolumn{3}{c}{ W.Nr. 1.7131 } & & \multicolumn{3}{c}{ W.Nr. 1.2379 } \\
\hline Thin coating & ta-C & WC/C & TiC/C & ta-C & WC/C & TiC/C \\
$H[G P a]$ & $24 \pm 2$ & $12 \pm 2$ & $28 \pm 2$ & $33 \pm 2$ & $9 \pm 1$ & $26 \pm 2$ \\
$E[G P a]$ & $270 \pm 22$ & $127 \pm 31$ & $340 \pm 22$ & $391 \pm 46$ & $99 \pm 11$ & $333 \pm 22$ \\
$H / E$ & 0.089 & 0.094 & 0.082 & 0.084 & 0.091 & 0.078 \\
\hline
\end{tabular}

The applied thin coatings significantly increased the base surface hardness; the highest nanohardness values were measured for the thin coatings labeled ta-C (24 - 33 GPa) and TiC/C (26 - $28 \mathrm{GPa})$, see Table 3.

\subsection{Scratch test results}

Three measurements were taken at different points for each sample, and the average values of the measured critical loads $\left(L_{C}\right)$ are given in Table 4. Based on the scratch tests, the critical load corresponding to a load leading to the appearance of the first crack $L_{c 1}$ (cohesive failure) lied within the range of $16-22 \mathrm{~N}$, and the next critical load $L_{C 3}$ (adhesion failure) lied within the range of $45-59 \mathrm{~N}$.

Table 4 The adhesion properties of the investigated coatings in $[\mathrm{N}]$

\begin{tabular}{lcccccc}
\hline Steel substrate & \multicolumn{3}{c}{ W.Nr. 1.7131 } & & \multicolumn{3}{c}{ W.Nr. 1.2379 } \\
\hline Thin coating & ta-C & WC/C & TiC/C & ta-C & WC/C & TiC/C \\
$L_{C 1}[N]$ & $21.8 \pm 1.3$ & $16.5 \pm 1.4$ & $18.1 \pm 1.9$ & $20.7 \pm 1.2$ & $16.5 \pm 2.4$ & $16.3 \pm 2.4$ \\
$L_{C 3}[N]$ & $56.5 \pm 4.2$ & $48.4 \pm 4.8$ & $44.7 \pm 2.4$ & $58.8 \pm 3.6$ & $50.3 \pm 5.3$ & $47.7 \pm 3.5$ \\
\hline
\end{tabular}

The measured adhesion values show that all of the types of surface modification have very good adhesion to the base material (W.Nr. 1.7131 and W.Nr. 1.2379). The best adhesion properties were measured with the thin coating of amorphous carbon (ta-C) on both types of substrate.

\subsection{Evaluation of the wettability of nanocomposite surfaces}

The wettability evaluation was performed according to the described methodology and the measurement results together with the standard deviation are shown in Table 5.

Table 5 Measured values of contact angle on the surface of the investigated coatings in $\left[^{\circ}\right]$

\begin{tabular}{lcccccc}
\hline Steel substrate & \multicolumn{3}{c}{ W.Nr. 1.7131 } & & \multicolumn{3}{c}{ W.Nr. 1.2379 } \\
\hline Thin coating & ta-C & WC/C & TiC/C & ta-C & WC/C & TiC/C \\
with distilled water $\left[{ }^{\circ}\right]$ & $79 \pm 5$ & $89 \pm 4$ & $82 \pm 4$ & $76 \pm 5$ & $83 \pm 3$ & $86 \pm 5$ \\
with oil PAR.CLP $320\left[^{\circ}\right]$ & $52 \pm 4$ & $54 \pm 3$ & $50 \pm 2$ & $52 \pm 2$ & $57 \pm 4$ & $53 \pm 4$ \\
\hline
\end{tabular}

The measured values indicate surfaces with hydrophilic properties, contact angles using distilled water and oil with the trade name Paramo CLP 320 were less than $90^{\circ}$. 


\subsection{Homogeneity and thickness of the thin coatings}

The thickness and homogeneity of the coatings was evaluated from their cuts (Figure 2). The evaluation was performed by linear and area analysis of chemical composition and using an SE detector.
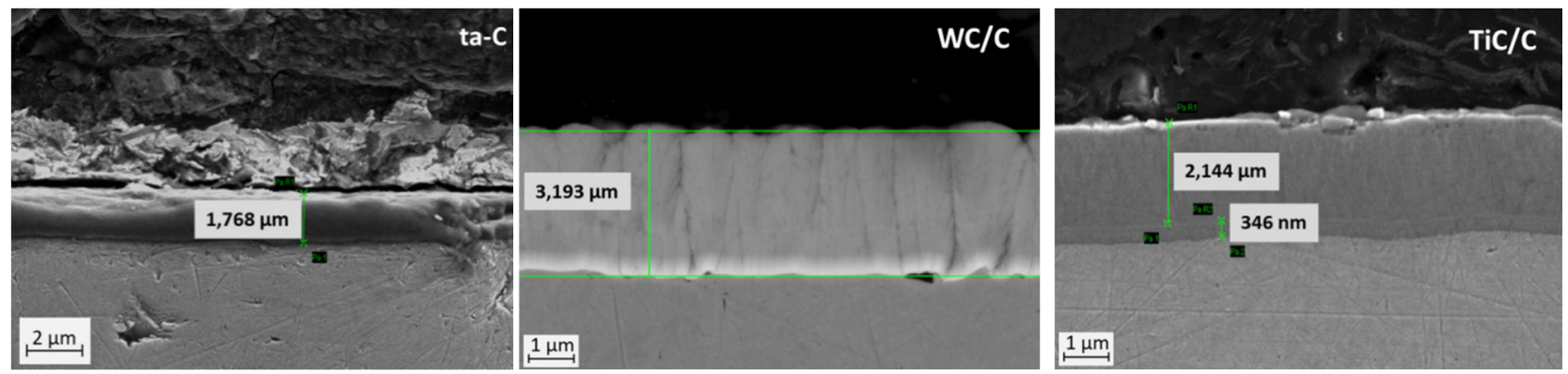

Figure 2 Thickness of the evaluated coatings of ta-C, WC/C and TiC/C displayed by means of cuts, by SEM

The ta- $C, W C / C, T i C / C$ coatings were cast into the resin and polished with diamond paste, and the ta- $C$ layers had to be silver plated. The thin layers deposited on the steel substrates (W.Nr. 1.7131 and W.Nr. 1.2379) are highly homogeneous. No major defects or cracks were observed on the coatings or on the boundaries of the coatings - substrate.

\subsection{Tribological behavior and surface wear rate}

A comparison of the changes in friction coefficients is made firstly by contacting the observed coatings with an $\mathrm{Al}_{2} \mathrm{O}_{3}$ ceramic ball. Furthermore, the nanostructured surfaces were evaluated using a lubricating medium (Paramo CLP 320), while the counterpart remained of the same material $\left(\mathrm{Al}_{2} \mathrm{O}_{3}\right)$. The working temperature of the oil during the tribological experiment was $45^{\circ} \mathrm{C}$. The last part of the experiment was conducted with the addition of the Paramo CLP 320 oil with nanoparticles $\left(\mathrm{SiO}_{2} \mathrm{NPs}\right.$ and $\mathrm{SiO}_{2}+\mathrm{Al}_{2} \mathrm{O}_{3} \mathrm{NPs}$ at a concentration of $0.5 \mathrm{~g} / \mathrm{L})$ under the same conditions.

Table 6 Measured values of coefficient of friction and their standard deviations

\begin{tabular}{|c|c|c|c|c|c|c|c|c|}
\hline Thin coating & W.Nr. & ta- $C$ & WCIC & TiCIC & W.Nr. & ta-C & WC/C & $\mathrm{TiC} / \mathrm{C}$ \\
\hline $\mathrm{CoF}[-]$ & & & & & $1.23 / 9$ & & & \\
\hline dry friction & $0.67 \pm 0.07$ & $0.11 \pm 0.01$ & $0.19 \pm 0.01$ & $0.25 \pm 0.03$ & $0.68 \pm 0.18$ & $0.10 \pm 0.01$ & $0.20 \pm 0.02$ & $0.24 \pm 0.02$ \\
\hline CLP 320 & $0.12 \pm 0.01$ & $0.11 \pm 0.01$ & $0.12 \pm 0.02$ & $0.13 \pm 0.02$ & $0.13 \pm 0.01$ & $0.09 \pm 0.01$ & $0.11 \pm 0.02$ & $0.12 \pm 0.02$ \\
\hline $\mathrm{SiO}_{2} \mathrm{NPS}$ & - & $0.10 \pm 0.01$ & $0.12 \pm 0.01$ & - & - & $0.10 \pm 0.01$ & $0.13 \pm 0.02$ & - \\
\hline $\mathrm{SiO}_{2}+\mathrm{Al}_{2} \mathrm{O}_{3} \mathrm{NPs}$ & - & $0.11 \pm 0.01$ & $0.12 \pm 0.01$ & - & - & $0.10 \pm 0.01$ & $0.11 \pm 0.01$ & - \\
\hline
\end{tabular}

The evaluation of the coefficient of friction in the lubricating medium Paramo CLP 320 (Figure 3 left) with the addition of $\mathrm{SiO}_{2} \mathrm{NPs}$ (Figure 3 center) and $\mathrm{SiO}_{2}+\mathrm{Al}_{2} \mathrm{O}_{3} \mathrm{NPs}$ (Figure 3 right) was performed on thin layers of ta-C and WC/C, the layers showed the lowest values of CoF during dry friction. Figure 3 shows the amount of wear of the thin coatings labeled ta-C upon contact with the $\mathrm{Al}_{2} \mathrm{O}_{3}$ ceramic ball and use of oil with and without nanoparticle additivation.

Lubricant friction had a beneficial effect on the CoF and wear of the friction pair. It was further determined that the nanoparticles had no effect on the size of the CoF (see Table 6). The addition of the $\mathrm{SiO}_{2} \mathrm{NPs}_{\mathrm{s}}$ to the 
lubricant (Paramo CLP 320) had a positive impact on the wear process, resulting in a reduction in the size of the damaged area after tribology (Figure 3 - right). Conversely, the combination of nanoparticles $\left(\mathrm{SiO}_{2}+\mathrm{Al}_{2} \mathrm{O}_{3}\right.$ NPs) resulted in increased wear after the tribological process (Figure 3 - center) compared to the oil without additivation.
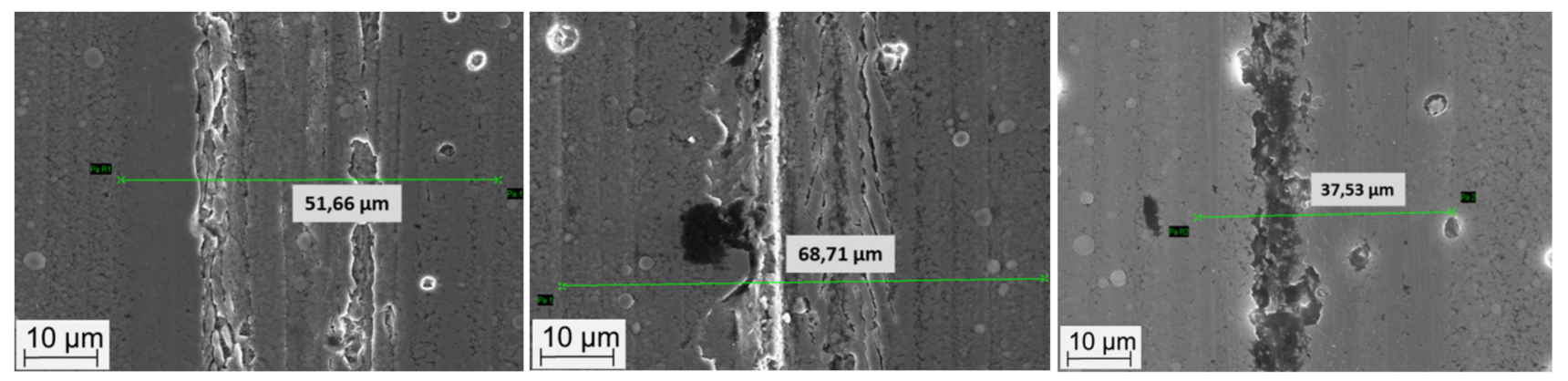

Figure 3 Wear of the amorphous carbon (ta-C) thin coating during friction with lubrication and after additivation of the oil by nanoparticles, evaluated by SEM

\section{CONCLUSION}

Three types of thin coatings (ta-C, WC/C and TiC/C) applied by low-voltage arc vapor deposition and magnetron sputtering were investigated. The study led to the following conclusions:

- Modification of the material surface with thin coatings leads to a slight increase in surface roughness.

- $\quad$ After the application of the thin coatings there was a significant increase in hardness on the surface of the test samples.

- $\quad$ The best adhesion to the base material was shown by the coating labeled ta- $C$ for both types of base material.

- The applied thin layers did not affect the wettability of the base material surfaces; the PARAMO CLP 320 oil used has a good surface wettability.

- The deposited thin coatings of ta-C, WC/C and TiC/C on the substrates reduced the CoF by up to $85 \%$. The coatings labeled ta-C and WC/C in combination with the PARAMO lubricant with $\mathrm{SiO}_{2} \mathrm{NP}$ additivation resulted in the best results, i.e. lower $\mathrm{CoF}$ and reduced wear.

\section{ACKNOWLEDGEMENTS}

This paper was supported through the project "Special transformation mechanisms in drives with electronic cams" Registration Number FV20547, obtained through the financial support of the Ministry of Industry and Trade in the program MIT TRIO and the Technical University of Liberec as part of the project of the Technical University of Liberec, Faculty of Mechanical Engineering with the support of the Institutional Endowment for the Long Term Conceptual Development of Research Institutes, as provided by the Ministry of Education, Youth and Sports of the Czech Republic in the year 2019. We are also grateful to PLATIT a.s. for the preparation of the thin coatings.

\section{REFERENCES}

[1] WIKLUND, U., M. NORDIN. Evaluation of a flexible physical vapor deposited TiC-C coating system. Surface and Coatings Technology. 2000, vol. 124, no. 2-3, pp. 154-161.

[2] MARKO, M., M. NORDIN. Friction of Tungsten-Based Coatings of Steel under Sliding Contact. Lubricants. 2019, vol. 7 , no. 2, pp. 154-161. 
[3] WANG, W., V. O. PELENOVICH. Microstructure, mechanical and tribological properties of WC/a-C: $\mathrm{H}$ coatings deposited by cathodic arc ion-plating. Vacuum. 2016, vol. 132, no. 2, pp. 31-39.

[4] EL MRABET, S., M.D. ABAD. Identification of the wear mechanism on WC/C nanostructured coatings: $\mathrm{H}$ coatings deposited by cathodic arc ion-plating. Surface and Coatings Technology. 2011, vol. 206, no. 7, pp. 1913-1920.

[5] WÄNSTRAND, O., M. LARSSON. Mechanical and tribological evaluation of PVD WC/C coatings: H coatings deposited by cathodic arc ion-plating. Surface and Coatings Technology. 1999, vol. 111, no.2-3, pp. 247-254.

[6] BARAGETTI, S., R. GEROSA. WC/C Coating Protection Effects on 7075-T6 Fatigue Strength in an Aggressive Environment: $\mathrm{H}$ coatings deposited by cathodic arc ion-plating. Procedia Engineering. 2014, vol. 74, no. 2-3, pp. 33-36.

[7] ERDEMIR, A., Ch. DONNET. Tribology of diamond-like carbon films: recent progress and future prospects. Journal of Physics D: Applied Physics. 2006, vol. 39, no. 18, pp. 311-327.

[8] ROCH, T., V. WEIHNACHT. Direct Laser Interference Patterning of tetrahedral amorphous carbon films for tribological applications: recent progress and future prospects. Diamond and Related Materials. 2013, vol. 33, no. 18, pp. 20-26.

[9] ABDULLAH TASDEMIR, H., M. WAKAYAMA. Wear behaviour of tetrahedral amorphous diamond-like carbon (taC DLC) in additive containing lubricants: recent progress and future prospects. Wear. 2013, vol. 307, no. 1-2, pp. 1-9.

[10] KOSKINEN, J., H. RONKAINEN. Low friction ta-C films with hydrogen reservoirs: recent progress and future prospects. Diamond and Related Materials. 2001 vol. 10, no. 3-7, pp. 1030-1035.

[11] MUSIL, J., P. NOVÁK. Tribological and mechanical properties of nanocrystalline-TiC/a-C nanocomposite thin films: recent progress and future prospects. Diamond and Related Materials. 2010, vol. 28, no. 2, pp. $244-249$.

[12] BAKALOVA, T., N. PETKOV. Monitoring Changes in the Tribological Behaviour of CrCN Thin Layers with Different $\mathrm{CH} 4 / \mathrm{N} 2$ Gas Ratios at Room and Elevated Temperatures: recent progress and future prospects. Manufacturing Technology. 2018, vol. 18, no. 4, pp. 533-537.

[13] PETKOV, N., T. BAKALOVA. Cathodic Arc Deposition of TiCN Coatings - Influence of the C2H2/N2 Ratio on the Structure and Coating Properties. Journal of Nano Research. 2018, vol. 51, no. 4, pp. 78-91. 